\title{
Percentage of acute stroke patients eligible for endovascular treatment
}

Darin B. Zahuranec, MD, MS

Jennifer J. Majersik, MD, MS

Correspondence \& reprint requests to Dr. Zahuranec: zdarin@umich.edu or Dr. Majersik: jennifer.majersik@hsc.utah.edu

\section{ABSTRACT}

Endovascular treatment for acute ischemic stroke has the potential to substantially improve the outcome for select individual stroke patients. However, the impact of this treatment on a population scale is unknown. We reviewed the epidemiology of acute stroke presentation times to estimate the proportion of patients with ischemic stroke who may be eligible for intra-arterial treatment. Experience with IV thrombolysis suggests that time from symptom onset is likely to be among the major exclusion criteria for intra-arterial treatment. Studies reviewed suggest that between $5 \%$ and $13 \%$ of patients with ischemic stroke present in the commonly recommended intra-arterial treatment window of 3 to 6 hours. Because of clinical exclusion factors other than time, the proportion of stroke patients eligible for intra-arterial treatment is likely even lower than these estimates. Clinicians and researchers should consider this a modest proportion of eligible patients when planning future studies and creating referral networks for endovascular stroke treatment. Neurology ${ }^{\circledR} 2012 ; 79$ (Suppl 1):S22-S25

\section{GLOSSARY}

AIS = acute ischemic stroke; BASIC $=$ Brain Attack Surveillance in Corpus Christi; CASPR = California Acute Stroke Pilot Registry; IA = intra-arterial; NIHSS = NIH Stroke Scale; PROACT = Prolyse in Acute Cerebral Thromboembolism; tPA = tissue plasminogen activator.

Endovascular therapy for acute ischemic stroke (AIS) is a promising treatment that has made vast strides in recent years yet remains in its early phases. Although potentially there is substantial benefit to intra-arterial (IA) treatment in some individuals with AIS, the benefit of this treatment on a population scale is unknown.

Delay in presentation is the major reason that patients with AIS are not eligible for treatment with IV tissue plasminogen activator (tPA). ${ }^{1,2}$ One of the potential advantages of IA stroke treatment is that some patients who are ineligible for treatment with IV tPA may be candidates for IA treatment because of a longer treatment time window. But how many AIS patients could benefit from IA treatment? In an attempt to answer this question, we briefly review selected studies describing the epidemiology of acute stroke presentation.

ELIGIBILITY FOR IA STROKE TREATMENT Success of IA treatment lies in the careful selection of patients who are mostly likely to benefit from its use. This selection process requires rapid evaluation of not only the presenting stroke syndrome but also comorbidities and patient preferences for aggressiveness of treatment in the setting of severe acute illness. Mobilization of the full interventional team can add additional delay to an already time-critical decision-making process.

American Stroke Association guidelines suggest that IA treatment is an option within 6 hours for AIS patients with major stroke due to middle cerebral artery occlusion who are not candidates for IV thrombolysis (Class I, level of evidence B). ${ }^{3}$ IA thrombolysis is also considered in some centers as rescue therapy for persistent large-vessel occlusion after IV thrombolytic treatment or after use of imaging techniques to assist in patient selection. Clinical trials to evaluate these strategies are still ongoing, and there are no universally accepted criteria to define the appropriate candidates for IA treatment in these scenarios. Selection is therefore left largely to the individual clinician.

From the Stroke Program (D.B.Z), University of Michigan Medical School, Ann Arbor; and Stroke Center (J.J.M.), Department of Neurology, University of Utah, Salt Lake City.

Go to Neurology.org for full disclosures. Disclosures deemed relevant by the authors, if any, are provided at the end of this article. 


\begin{tabular}{|c|c|c|c|c|c|c|c|c|c|}
\hline \multirow[b]{2}{*}{ Study author, year } & \multirow[b]{2}{*}{ Location } & \multirow[b]{2}{*}{ Study population } & \multirow[b]{2}{*}{ No. } & \multirow[b]{2}{*}{$\begin{array}{l}\text { Median } \\
\text { NIHSS }\end{array}$} & \multicolumn{5}{|c|}{$\begin{array}{l}\text { Percentage presenting at } \\
\text { indicated no. of hours post onset }\end{array}$} \\
\hline & & & & & $0-3$ & $3-6$ & $6-24$ & $>24$ & Unknown \\
\hline Majersik et al., $2007^{7}$ & Southeast Texas & Population-based & 2,347 & 4 & 27 & 13 & 29 & 24 & 6 \\
\hline Owe et al., $2006^{17}$ & Bergen, Norway & 3 Selected hospitals & 88 & 4 & 23 & 8 & $69^{b}$ & & \\
\hline Qureshi et al., $2005^{9}$ & Western New York & $\begin{array}{l}11 \text { Selected hospitals, } \\
\text { including } 8 \text { academic } \\
\text { centers }\end{array}$ & 1,590 & $3-5$ & 21 & 11 & 19 & 26 & 22 \\
\hline $\begin{array}{l}\text { Kleindorfer et al., } \\
2004^{8}\end{array}$ & Ohio, Kentucky & $\begin{array}{l}\text { Population-based, } \\
\text { including } 1 \text { academic } \\
\text { center }\end{array}$ & 1,849 & NR & 22 & 5 & 51 & & 22 \\
\hline Kothari et al., $1999^{19}$ & Ohio, Kentucky & $\begin{array}{l}4 \text { Selected hospitals, } \\
\text { including } 1 \text { academic } \\
\text { center }\end{array}$ & 151 & NR & 30 & 10 & 21 & 18 & 21 \\
\hline $\begin{array}{l}\text { Azzimondi et al., } \\
1997^{12}\end{array}$ & Bologna, Italy & 1 Teaching hospital & 204 & NR & 40 & 12 & 31 & 9 & 7 \\
\hline
\end{tabular}

Abbreviations: CASPR $=$ California Acute Stroke Pilot Registry; NIHSS $=$ NIH Stroke Scale; NR = not reported.

a Table is adapted from Majersik et al. ${ }^{7}$

b Includes patients with "overnight onset."

It is difficult to estimate the proportion of stroke patients eligible for IA treatment, as most large population-based studies do not provide sufficient detail of all possible exclusion criteria (such as large preexisting infarct on imaging). The Prolyse in Acute Cerebral Thromboembolism-II (PROACT) Trial, which remains the largest randomized placebo-controlled trial of IA thrombolysis to date, supports the idea that time and mild stroke symptoms are likely to be major exclusions for IA treatment. Of 12,323 screened patients at 54 centers over $2 \frac{1}{2}$ years, $180(1.5 \%)$ were randomized, ${ }^{4}$ with half of the exclusions due to presentation after 6 hours or for minor or improving stroke.

This review therefore focuses on the epidemiology of acute stroke presentation times and stroke severity, as these factors are likely to be the most common contraindications for IA treatment and have been well defined in studies to date. We concentrate on the 3- to 6-hour time window, as the 6-hour window for IA treatment is currently recommended by recent American Stroke Association Guidelines, ${ }^{2}$ and arrival times within this time window have been commonly reported. Studies reviewed were performed prior to the expansion of the time window for IV treatment to 4.5 hours $^{5}$ and do not report time in sufficient detail to allow differentiation of presentation times before or after 4.5 hours. However, examining the 3- to 6-hour window can still provide a useful estimate of the upper limit of the proportion of patients who may be eligible for IA treatment.

Studies of acute stroke presentation. For this review, it is appropriate to focus on population-based studies that attempt to capture every stroke within a defined geographic region, as they provide a more accurate estimate of the epidemiology of acute stroke presentation. Studies from single academic centers may be subject to local referral biases that substantially alter the spectrum of patient arrival times and stroke severity. A summary of the studies discussed here, as well as several other studies not discussed in detail, is presented in the table. A Medline search was performed to identify studies describing presentation times for acute stroke that detailed presentation times at a minimum in blocks of $0-3$ and 3-6 hours; references of the individual articles were also reviewed for relevance. Studies were excluded if they included patients with intracerebral hemorrhage, if they excluded individuals with unknown presentation times, or if they defined time to presentation as "first time seen sick" rather than "last time known well."

Brain Attack Surveillance in Corpus Christi. The Brain Attack Surveillance in Corpus Christi (BASIC) study is an ongoing population-based stroke surveillance study that uses a combination of active and passive surveillance to capture all strokes in individuals $\geq 45$ years old in Nueces County, Texas. ${ }^{6}$ One unique aspect of BASIC is that there is no academic medical center in this community, and therefore it provides insight into the "real world" community experience of stroke care. The study reported presentation times of 2,347 AIS patients between January 2000 and June 2005 . $^{7}$ When a precise time of onset 
was not available, presentation time was estimated from the medical record. In this study, only $13 \%$ of cases arrived between 3 and 6 hours of symptom onset. More important, approximately half of those with moderate to severe strokes (NIH Stroke Scale [NIHSS] score $>7$ ) arrived within 3 hours of symptom onset.

Greater Cincinnati-Northern Kentucky. The populationbased Greater Cincinnati-Northern Kentucky Stroke Study yielded data on patient arrival times from July 1993 through June $1994 .^{8}$ During the study period, 1,849 individuals with AIS presented to an emergency department. Only 5\% of patients presented within 3 to 6 hours of symptom onset. The researchers also found that it was primarily patients with less severe stroke who presented late, as $54 \%$ of patients arriving after 3 hours (or with unknown onset time) had an NIHSS score of $<5$.

Buffalo-Erie County. A study of hospital arrival times in Erie County in Western New York yielded data on 1,590 patients with AIS presenting between January and December 2000. ${ }^{9}$ Time interval from symptom onset to hospital arrival was 3 to 6 hours for $11 \%$. Similar to other studies, the researchers found that patients with lower NIHSS scores presented later than those with higher NIHSS scores.

California Acute Stroke Pilot Registry. The California Acute Stroke Pilot Registry (CASPR) collected data on patient arrival times at 11 California hospitals in 5 major population regions throughout the state. ${ }^{10}$ The registry identified 374 cases with AIS from November 2002 through January 2003. Overall, 6\% presented in the 3- to 6-hour window. The CASPR report authors also estimated the impact of expanding the thrombolytic time window, by assuming that patients arriving between 3 and 6 hours were treated in the same relative proportion as those arriving within 3 hours. The authors estimated that expanding the treatment window from 3 to 6 hours would increase the proportion of patients treated with IV thrombolysis from $4.3 \%$ to $8.3 \%$. Although this estimate does not directly translate to the proportion of patients eligible for IA treatment within the 3- to 6-hour window, it may be a reasonable approximation.

Limitations of existing studies. This review is limited in its ability to truly estimate the proportion of AIS patients eligible for endovascular treatment. Because of categorical reporting of time variables, it is difficult to assess the eligibility of patients arriving just before the end of the time window who may not be able to have an assessment completed rapidly enough to receive IV or IA thrombolysis. This review did not address the issue of treatment between 6 and 8 hours, as has been suggested when mechanical clot retrieval devices are utilized. ${ }^{11}$ The limited data suggest that a low proportion of stroke patients $(\sim 3 \%)$ arrive within this time window. ${ }^{12}$

DISCUSSION Studies reviewed suggest that between $5 \%$ and $13 \%$ of AIS patients present within the 3- to 6-hour treatment window. Individuals presenting after 3 hours tend to have less severe strokes than those who present early and are therefore less likely to have a large-vessel occlusion amenable to IA treatment. Because many patients will have contraindications other than time from onset, this estimate should be considered the likely upper-bound proportion of patients eligible for IA treatment, unless there is a dramatic shift in patient arrival times or an expansion of the eligibility criteria for IA treatment.

Several ongoing clinical trials may alter the proportion of patients eligible for IA treatment. The Interventional Management of Stroke III trial is comparing the safety and efficacy of IV followed by IA treatment to standard IV treatment alone. ${ }^{13}$ Other studies are comparing primary IA treatment to IV tPA within 3 hours. ${ }^{14}$ Although these treatment strategies may have theoretical advantages for selected patients, there is no current evidence of the superiority of either primary IA treatment or combined IV-IA approaches in patients otherwise eligible for standard IV tPA treatment. Other studies are investigating the possibility of further expanding the IV treatment window out to 6 hours in selected patients. The proportion of patients eligible for endovascular stroke treatment in the future may certainly change, depending on the results of these and other clinical trials.

Several conclusions can be drawn from the relatively modest proportion of AIS patients who currently present within the appropriate time window for endovascular therapy. First, centers that offer endovascular treatment for AIS will need to set up mechanisms for rapid transfer of potential treatment candidates from surrounding facilities, in order to maintain adequate treatment volumes and hands-on experience. The increasing availability of telestroke networks may play an important role in facilitating patient access to centers that offer IA treatment. ${ }^{15}$ Second, based on the considerable cost of maintaining such a referral network and continuous readiness to deliver IA treatment, cost-effectiveness studies of IA stroke treatment from the societal perspective should be performed. Finally, additional resources and effort should be directed toward reducing patient delays in seeking initial treatment for stroke. ${ }^{10,16}$ Simply improving public knowledge of stroke symptoms is insufficient to reduce delays; future studies 
will need to address the complex social and cognitive factors that contribute to delays in presentation. ${ }^{16}$ Whereas indications and specific techniques for IA treatment may change with the results of ongoing trials and new device development, addressing the issue of delay time will increase access for all stroke patients to current and future IV and IA reperfusion strategies.

\section{AUTHOR CONTRIBUTIONS}

Both authors contributed to drafting/revising the manuscript, study concept or design, analysis or interpretation of data, and statistical analysis.

\section{DISCLOSURE}

Dr. Zahuranec received speaker honoraria from the Society of Vascular and Interventional Neurology and received research support from NIH/ NINDS, AHRQ, and Medtronic. Dr. Majersik receives research support from the NIH and the National Cancer Institute. Go to Neurology.org for full disclosures.

Received June 28, 2011. Accepted in final form August 17, 2011.

\section{REFERENCES}

1. Barber PA, Zhang J, Demchuk AM, Hill MD, Buchan AM. Why are stroke patients excluded from TPA therapy? An analysis of patient eligibility. Neurology 2001;56: 1015-1020.

2. Adams HP Jr, del Zoppo G, Alberts MJ, et al. Guidelines for the early management of adults with ischemic stroke: a guideline from the American Heart Association/American Stroke Association Stroke Council, Clinical Cardiology Council, Cardiovascular Radiology and Intervention Council, and the Atherosclerotic Peripheral Vascular Disease and Quality of Care Outcomes in Research Interdisciplinary Working Groups. Stroke 2007;38:1655-1711.

3. Jauch EC, Cucchiara B, Adeoye O, et al. Part 11: adult stroke: 2010 American Heart Association Guidelines for Cardiopulmonary Resuscitation and Emergency Cardiovascular Care. [erratum appears in Circulation 2011; 124(15):e404]. Circulation 2010;122(18 suppl 3):S818 S828.

4. Furlan A, Higashida R, Wechsler L, et al. Intra-arterial prourokinase for acute ischemic stroke: the PROACT II study: a randomized controlled trial: Prolyse in Acute Cerebral Thromboembolism. JAMA 1999;282:2003-2011.

5. Del Zoppo GJ, Saver JL, Jauch EC, Adams HP Jr. Expansion of the time window for treatment of acute ischemic stroke with intravenous tissue plasminogen activator: a science advisory from the American Heart Association/American Stroke Association. Stroke 2009; 40:2945-2948.
6. Morgenstern LB, Smith MA, Lisabeth LD, et al. Excess stroke in Mexican Americans compared with nonHispanic whites: the Brain Attack Surveillance in Corpus Christi Project. Am J Epidemiol 2004;160:376-383.

7. Majersik JJ, Smith MA, Zahuranec DB, Sanchez BN, Morgenstern LB. Population-based analysis of the impact of expanding the time window for acute stroke treatment. Stroke 2007;38:3213-3217.

8. Kleindorfer D, Kissela B, Schneider A, et al. Eligibility for recombinant tissue plasminogen activator in acute ischemic stroke: a population-based study. Stroke 2004;35: e27-e29.

9. Qureshi AI, Kirmani JF, Sayed MA, et al. Time to hospital arrival, use of thrombolytics, and in-hospital outcomes in ischemic stroke. Neurology 2005;64:2115-2120.

10. California Acute Stroke Pilot Registry (CASPR) Investigators. Prioritizing interventions to improve rates of thrombolysis for ischemic stroke. Neurology 2005;64:654-659.

11. Smith WS, Sung G, Starkman S, et al. Safety and efficacy of mechanical embolectomy in acute ischemic stroke: results of the MERCI trial. Stroke 2005;36:1432-1438.

12. Azzimondi G, Bassein L, Fiorani L, et al. Variables associated with hospital arrival time after stroke: effect of delay on the clinical efficiency of early treatment. Stroke 1997; 28:537-542.

13. Khatri P, Hill MD, Palesch YY, et al. Methodology of the Interventional Management of Stroke III Trial. Int J Stroke 2008;3:130-137.

14. Intra-arterial Versus Systemic Thrombolysis for Acute Ischemic Stroke (SYNTHESIS EXP). Available at: www.clinical trials.gov/ct2/show/NCT00640367?term $=$ NCT00640367\& rank $=1$. Accessed August 9, 2011.

15. Schwamm LH, Holloway RG, Amarenco P, et al. A review of the evidence for the use of telemedicine within stroke systems of care: a scientific statement from the American Heart Association/American Stroke Association. Stroke 2009; 40:2616-2634.

16. Moser DK, Kimble LP, Alberts MJ, et al. Reducing delay in seeking treatment by patients with acute coronary syndrome and stroke: a scientific statement from the American Heart Association Council on Cardiovascular Nursing and Stroke Council. Circulation 2006;114:168-182.

17. Owe JF, Sanaker PS, Naess H, Thomassen L. The yield of expanding the therapeutic time window for tPA. Acta Neurol Scand 2006;114:354-357.

18. Koennecke HC, Nohr R, Leistner S, Marx P. Intravenous tPA for ischemic stroke team performance over time, safety, and efficacy in a single-center, 2-year experience. Stroke 2001;32:1074-1078.

19. Kothari R, Jauch E, Broderick J, et al. Acute stroke: delays to presentation and emergency department evaluation. Ann Emerg Med 1999;33:3-8. 


\title{
Neurology
}

\author{
Percentage of acute stroke patients eligible for endovascular treatment \\ Darin B. Zahuranec and Jennifer J. Majersik \\ Neurology 2012;79;S22-S25 \\ DOI 10.1212/WNL.0b013e31826957cf
}

This information is current as of September 24, 2012

\section{Updated Information \&}

Services

References

Subspecialty Collections

Permissions \& Licensing

Reprints including high resolution figures, can be found at:

http://n.neurology.org/content/79/13_Supplement_1/S22.full

This article cites 18 articles, 12 of which you can access for free at: http://n.neurology.org/content/79/13_Supplement_1/S22.full\#ref-list-1

This article, along with others on similar topics, appears in the following collection(s):

\section{All Cerebrovascular disease/Stroke}

http://n.neurology.org/cgi/collection/all_cerebrovascular_disease_strok e

All epidemiology

http://n.neurology.org/cgi/collection/all_epidemiology

Information about reproducing this article in parts (figures,tables) or in its entirety can be found online at:

http://www.neurology.org/about/about_the_journal\#permissions

Information about ordering reprints can be found online:

http://n.neurology.org/subscribers/advertise

Neurology ${ }^{\circledR}$ is the official journal of the American Academy of Neurology. Published continuously since 1951, it is now a weekly with 48 issues per year. Copyright Copyright $@ 2012$ by AAN Enterprises, Inc.. All rights reserved. Print ISSN: 0028-3878. Online ISSN: 1526-632X.

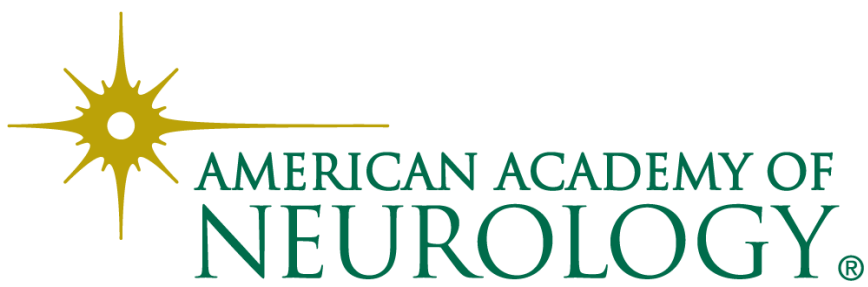

